\title{
Carry Trade Profitability Using Pegged Currency: A Case of the Qatari Riyal
}

\author{
Musaed S. AlAli ${ }^{1} \&$ Yaser A. AlKulaib ${ }^{2}$ \\ ${ }^{1}$ School of Economics, Finance and Marketing, RMIT, Australia \\ ${ }^{2}$ College Of Business Administration, Kuwait University, Kuwait \\ Correspondence: Musaed S. AlAli, School of Economics, Finance and Marketing, RMIT University, Melbourne, \\ Victoria., Australia. Tel: 0061-405-439-363. E-mail: musaed.al-ali@rmit.edu.au
}

Received: August 1, 2015

Accepted: August 24, 2015

Online Published: September 25, 2015

doi:10.5539/ijef.v7n10p215

URL: http://dx.doi.org/10.5539/ijef.v7n10p215

\begin{abstract}
Carry trade is an investment strategy in which investors borrow low-yield currency and invest it in a high-yield currency, hoping to profit from the interest-rate differential. Based on uncovered interest parity (UIP), carry trade should not work, but studies have shown that UIP does not hold. This failure has led to unprecedented returns for that strategy, outperforming the S\&P 500 in terms of the Sharpe ratio. This paper examines the profitability in using pegged currency in such a strategy. While carry trade is performed largely with currencies that adapt floating exchange rate system, conducting such a strategy using pegged currency has proven to be very rewarding, especially when the strategy is enhanced with forecasting methods.
\end{abstract}

Keywords: carry trade, random walk, uncovered interest parity (UIP)

\section{Introduction}

Despite Jorda and Taylor (2012) describing it as a naïve trading strategy, carry trade has shown that it is a very rewarding strategy. Not only does carry trade produce returns similar to those of the S\&P 500, as confirmed by Burnside et al. (2006), Dunis and Miao (2007), Moosa (2008), Darvas (2009), Menkhoff et al. (2012), and Jurek (2014), but it is also less risky, producing a better Sharpe ratio (Gyntelberg \& Remolona, 2007). Brunnermeier and Pedersen (2009) concluded that carry trade returns are much less variable than stock returns, with an annualized standard deviation of about 5 percent (compared to about 15 percent for stocks); as a result, the Sharpe ratio of the carry trade is double that of stock. Burnside et al. (2007) conducted a study spanning 1997-2006 using the U.S. dollar as the funding currency in carry trade. They reported that carry trade is a profitable strategy producing an annualized Sharpe ratio of 1.32 compared to 0.23 for the U.S. stock market. Moosa (2008) conducted a study between six pairs of currencies (two funding currencies - JPY and CHF - and three investment currencies-USD, GBP, and CAD) for the period of January 1996 to April 2006 and showed that carry trade can be profitable over a long period of time, producing annualized rates of return ranging between $3.40 \%$ and $9.04 \%$. Further, Jylha and Suominen (2011) conducted a study of 11 major currencies for the period of January 1979 to December 2008 and found the simplest form of carry trade produced a mean monthly return of $0.47 \%$ with a standard deviation of $2.06 \%$, producing a monthly Sharpe ratio of 0.228 .

Explaining carry trade payoffs presents a difficult challenge for researchers. Researchers have failed to establish statistically significant correlation between the payoffs of carry trade and the traditional risk factors. Barroso and Santa-Clara (2013) argue that conventional stock market risk factors do not explain carry trade returns at all - the same conclusion is reached by Burnside et al. (2011) as they contend that the high payoffs on carry trade represent a compensation for bearing a risk. They argue that it is difficult to explain the profitability of carry trade with conventional risk factors. Moosa (2008) points out that, unlike stock market investment, high Sharpe ratios do not necessarily represent compensation for risk because the payoff is not associated with standard risk factors.

Carry trade owes its success to the failure of uncovered interest rate parity (UIP). Gyntelberg and Remolona (2007) described it as nothing more than a bet against UIP. Baillie and Chang (2011) agreed when they described carry trade as a speculation against UIP. UIP is an arbitrage condition indicating there should be no profit opportunity from the differences in interest rates between two currencies. According to UIP, high interest rate 
currency should depreciate against the low interest rate currency by the interest rate differential. However, this is not the case. It has been noticed that currencies with higher interest rates tend to appreciate against low interest rate currencies, contradicting UIP.

While many researchers - such as Gyntelberg (2007), Baillie and Chang (2011), and others - tend to imply a link between the failures of UIP and profitability, Moosa and Halteh (2012) stated, although the failure of UIP is a necessary condition for a profitable carry trade, it is not a sufficient enough condition. They argued that big movements in the foreign exchange markets might offset the interest rate differential and might even produce a losing position. Thus, carry trades tend to thrive on high interest rate differential and low exchange rate volatility. Embedding a forecasting element in the carry trade decision-making process could enhance profitability and improve risk-adjusted returns, as concluded by Moosa and Halteh (2012), Li (2011), Schmidbauer et al. (2010), Moosa (2010), Jorda and Taylor (2012), and others. For example, Della Corte et al. (2009) found there is significant economic benefit to an investor who exploits deviations from UIP by forecasting currency returns. In addition, $\mathrm{Li}$ (2011) evaluated the effectiveness of economic fundamentals in enhancing carry trade and found the profitability of carry trade and risk-return measures can be enhanced by using forecasts. Further, Bhatti (2012) found that the interest differential is not the only factor determining the return in carry trades; the expected change in the exchange rate of the funding against the target currency over the holding period also affects the return in carry trades. Moosa and Halteh (2012) agreed by stating that interest rate differential is not a good indicator for carry trade return.

Meese and Rogoff (1983) used error measures to evaluate the goodness of the forecasting model. The use of these measures led to the conclusion among researchers and practitioners that a naïve forecasting model would work just as well as professional forecasts. Chow et al. (2007) questioned the validity of such measures to evaluate the forecasting model by stating, "[I]t seems irrational for profit-maximizing firms to 'waste' millions of dollars generating and buying professional forecasts". Considering their findings, they suggested it might not be appropriate to use forecast error measures to judge the quality of professional forecasts and profit should be included as a judging criterion. Cheung et al. (2005) noted using criteria other than the mean square error (MSE) does not mean "changing the rules of the game" and minimizing the mean square error may not be important from an economic standpoint, implying that relying on mean square error may result in overlooking other important aspects of prediction, such as profitability, particularly at the long horizon. They also argued that direction of change is "perhaps more important from [the] market timing perspective".

With researchers exploring new measures to evaluate the forecasting models, Leitch and Tanner (1991) found a strong relation between direction accuracy and profitability but not between error measures and profitability. They argued the direction of change may be more relevant for profitability and economic concerns than the error measures and that measuring the forecasting accuracy based on the magnitude of the error has no predictable relation to profitability. Engle and Hamilton (1990) supported the use of direction accuracy, by describing it as "not a bad proxy for a utility-based measure of forecasting performance". West et al. (1993) suggested a utility-based evaluation of exchange rate predictability. Moosa and Burns (2012) agreed by stating that profitability is consistently related to direction accuracy while the random walk does not predict the direction. Moosa (2013) suggested that profitability is the ultimate test of forecasting accuracy.

\section{Method}

Two strategies will be tested in this paper. The first strategy is carry trade based only on interest rate differential, and the second is forecasting based and takes both interest rate differential and the forecasted exchange rate into consideration.

Let $i_{x}$ and $i_{y}$ be the interest rates for currencies $x$ and $y$, respectively. In addition, let $S$ be the spot rate between the two currencies measured as one unit of $y$ against $x$, so appreciation of $y$ against $x$ would result in a higher $S$, and vice versa.

Under carry trade, when $i_{y}>i_{x}$ then:

1). At time $t$, the carry trader would borrow $x$ at $i_{x}$ for the period $t$ to $t+1$.

2). That amount borrowed is converted to $y$ at $S_{t}$, obtaining $1 / S_{t}$ units of $y$. This amount is invested at $i_{y}$ for the period $t$ to $t+1$.

3). At $t+1$, the $y$ value of the investment will be $\left(1 / S_{t}\right)\left(1+i_{y}\right)$.

4). The $x$ currency value of the investment, converted at the spot rate prevailing at $t+1$, is $\left(S_{t+1} / S_{t}\right)\left(1+i_{y}\right)$.

5). At $t+1$, the loan on $x$ matures, and the amount $\left(1+i_{x}\right)$ has to be repaid. 
In this case the return on carry trade is given by

$$
\pi=\frac{s_{t+1}}{s_{t}}\left(1+i_{y}\right)-\left(1+i_{x}\right)
$$

which can be rewritten as

$$
\pi=\left(i_{y}-i_{x}\right)+\dot{S}_{t+1}
$$

where $\dot{S}_{t+1}$ is the percentage change in the exchange rate between $t$ and $t+1$. The carry trade operation is implicitly based on the assumption of random walk without drift (Moosa, 2004), which means that $\dot{S}_{t+1}=0$. Thus, carry trade is profitable as long as $\left(i_{y}-i_{x}\right)>-\dot{S}_{t+1}$. (That is, as long as the interest rate differential is larger than the depreciation of currency $y$ against currency $x$ ).

Because of the changes in interest rates differential, it is necessary to switch the role of the currencies, so the general formula for calculating the rate of return on the carry trade will be as follow:

$$
\pi=\left\{\begin{array}{lll}
\left(i_{y}-i_{x}\right)+\dot{S}_{t+1} & \text { if } & i_{y}>i_{x} \\
\left(i_{x}-i_{y}\right)-\dot{S}_{t+1} & i_{y}<i_{x}
\end{array}\right.
$$

The forecasting-based strategy involves calculating the expected rate of return and conducting the position accordingly. The expected return is calculated as follows:

$$
\pi^{e}=\left(i_{y}-i_{x}\right)+\dot{S}_{t+1}^{e}
$$

where $\dot{S}_{t+1}^{e}$ is the calculated percentage change in exchange rate based on the forecasting model. Thus, we go long $y$ and short $x$ if $\pi^{e}>0$ and vice versa. In that case, the profitability of the forecasting-based strategy is as follows:

$$
\pi=\left\{\begin{array}{lll}
\left(i_{y}-i_{x}\right)+\dot{S}_{t+1} & \text { if } & \pi^{e}>0 \\
\left(i_{x}-i_{y}\right)-\dot{S}_{t+1} & \pi^{e}<0
\end{array}\right.
$$

Since the Qatari riyal is pegged to the U.S. dollar at 3.64 Riyals per dollar, with a very narrow fluctuation band, the exchange rate of the riyal will reflect the economic conditions of the U.S. dollar. Thus, when calculating for $\dot{S}_{t+1}^{e}$ using the flexible price monetary model of exchange rates, we will be doing so for the U.S. dollar.

$$
s_{t}=\alpha_{0}+\alpha_{1}\left(m_{a, t}-m_{b, t}\right)+\alpha_{2}\left(y_{a, t}-y_{b, t}\right)+\alpha_{3}\left(i_{a, t}-i_{b, t}\right)+\varepsilon_{t},
$$

where $s$ is the log of the exchange rate, $m$ is the log of the money supply, $y$ is the log of the industrial production, $i$ is the $\log$ of the nominal interest rate, $\varepsilon$ is the error factor, and $a$ and $b$ refer to the countries whose currencies are involved. Here, country $b$ will have its currency as the base currency in the exchange rate pair. The forecasted exchange rate will be as follows:

$$
\hat{s}_{t+1}=\hat{\alpha}_{0}+\hat{\alpha}_{1}\left(m_{a, t+1}-m_{b, t+1}\right)+\hat{\alpha}_{2}\left(y_{a, t+1}-y_{b, t+1}\right)+\hat{\alpha}_{3}\left(i_{a, t+1}-i_{b, t+1}\right),
$$

where $\hat{\alpha}_{0}$ is the estimated value of $\alpha_{0}$ and so on. To convert the log forecasted exchange rate to estimated exchange rate, the following is applied:

$$
S_{t+1}^{e}=\exp \left(\hat{s}_{t+1}\right)
$$

$\dot{S}_{t+1}^{e}$ is calculated from $S_{t+1}^{e}$ and $S_{t}$, which can be used to calculate the expected return in equation (4).

\section{Data and Empirical Results}

The empirical results presented in this paper are based on six currency combinations involving the Qatari riyal (QAR), the Japanese yen (JPY), the British pound (GBP), the Korean won (KRW), the Singaporean dollar (SGD), the Canadian dollar (CAD), and the Swiss franc (CHF). Monthly data were used for the period of January 2001 to December 2011. Data were obtained from the International Financial Statistics (CD-ROM) and DataStream terminal.

Meese and Rogoff (1983) used error measurements to evaluate the forecasting model against the random walk. In terms of the magnitude of error measurements, table 1 shows the monetary model was not able to outperform the random walk in any pair. The error measuring criteria for the average of the six pairs are shown in table 2 . The mean absolute error (MAE) was 1.83 for the carry trade compared to 7.25 for the forecasting-based model. The mean square error (MSE) was 7.17 for the carry trade while, for the forecasting-based model, it was 91.22. In terms of RMSE, the results were 2.57 and 9.33 for the random walk and forecasting-based models, respectively. The 
Theil inequality coefficient $(\mathrm{U})$ indicates the findings in one number, confirming the superiority of random walk over forecasting models by showing no result below 1 .

Table 1. Results for individual pairs

\begin{tabular}{|c|c|c|c|c|c|c|c|c|c|c|c|c|}
\hline & \multicolumn{2}{|c|}{ SGD/QAR } & \multicolumn{2}{|c|}{ GBP/QAR } & \multicolumn{2}{|c|}{ JPY/QAR } & \multicolumn{2}{|c|}{ QAR/KRW } & \multicolumn{2}{|c|}{ CAD/QAR } & \multicolumn{2}{|c|}{ CHF/QAR } \\
\hline & CT & FC & CT & FC & CT & FC & CT & FC & CT & FC & CT & FC \\
\hline MAE & 1.1 & 4.5 & 1.9 & 6.2 & 2.0 & 7.7 & 2.1 & 8.4 & 1.4 & 6.9 & 2.5 & 9.8 \\
\hline MSE & 2.3 & 40.2 & 6.2 & 61.3 & 6.4 & 86.3 & 14.1 & 111.9 & 3.7 & 90.7 & 10.3 & 156.9 \\
\hline RMSE & 1.5 & 6.3 & 2.5 & 7.8 & 2.5 & 9.3 & 3.8 & 10.6 & 1.9 & 9.5 & 3.2 & 12.5 \\
\hline $\mathbf{U}$ & \multicolumn{2}{|c|}{4.16} & \multicolumn{2}{|c|}{3.14} & \multicolumn{2}{|c|}{3.66} & \multicolumn{2}{|c|}{2.81} & \multicolumn{2}{|c|}{4.95} & \multicolumn{2}{|c|}{3.91} \\
\hline Direction & \multicolumn{2}{|r|}{55.87} & \multicolumn{2}{|c|}{53.63} & \multicolumn{2}{|r|}{50.84} & & 61.45 & \multicolumn{2}{|r|}{48.60} & \multicolumn{2}{|c|}{50.28} \\
\hline Accuracy $\%$ & \multirow{2}{*}{\multicolumn{2}{|c|}{44.13}} & \multirow{2}{*}{\multicolumn{2}{|c|}{46.37}} & & & & & & & & \\
\hline $\begin{array}{c}\text { Confusion } \\
\text { Rate\% }\end{array}$ & & & & & \multicolumn{2}{|r|}{49.16} & & 38.55 & \multicolumn{2}{|r|}{51.40} & \multicolumn{2}{|r|}{49.72} \\
\hline $\begin{array}{c}\text { Interest Rate } \\
\text { Differential }\end{array}$ & \multicolumn{2}{|c|}{2.84} & \multicolumn{2}{|c|}{0.09} & \multicolumn{2}{|c|}{3.68} & \multicolumn{2}{|c|}{1.98} & \multicolumn{2}{|c|}{2.48} & \multicolumn{2}{|c|}{3.05} \\
\hline Mean Return & 0.202 & 0.200 & -0.042 & 0.143 & 0.109 & 0.348 & -0.16 & 0.88 & 0.07 & 0.12 & 0.08 & 0.11 \\
\hline $\begin{array}{c}\text { Cumulative } \\
\text { Return }\end{array}$ & 40.61 & 40.08 & -12.31 & 22.04 & 14.68 & 75.88 & -26.84 & 332.52 & 9.74 & 20.11 & 4.33 & 10.42 \\
\hline SD & 1.53 & 1.53 & 2.51 & 2.50 & 2.56 & 2.53 & 3.85 & 3.66 & 1.93 & 1.93 & 3.22 & 3.22 \\
\hline VaR 99\% & 3.53 & 4.78 & 8.48 & 6.50 & 6.09 & 4.66 & 11.61 & 5.29 & 4.88 & 4.10 & 6.34 & 6.38 \\
\hline VaR $95 \%$ & 1.69 & 1.95 & 3.69 & 3.60 & 4.37 & 3.47 & 4.91 & 3.12 & 2.86 & 2.59 & 4.98 & 4.58 \\
\hline
\end{tabular}

$\mathrm{CT}$ is carry trade and FC is the forecasting-based strategy.

In terms of mean return, carry trade produced positive returns in four of the six pairs; on the other hand, the forecasting-based strategy produced six pairs with positive mean returns. While SGD/QAR produced the highest mean return of $0.20 \%$ ( $2.43 \%$ annualized) in the carry trade, QAR/KRW showed the biggest return of $0.88 \%$ (10.60\% Annualized) in the forecasting-based strategy. The only negative returns were QAR/KRW and GBP/QAR, which were lower than the carry trade. The overall mean return for the six pairs was $0.51 \%$ for the carry trade, compared to $3.60 \%$ for the forecasting-based strategy. The mean return improved in five of the six pairs, except for that of SGD/QAR, in which the mean return for the carry trade exceeded the mean return of the forecasting-based strategy. On the cumulative return side, the forecasting-based strategy outperformed the carry trade in all the pairs, except for SGD/QAR, in which the cumulative return was better for the carry trade. While the pair that produced the highest cumulative return under the carry trade was SGD/QAR, with $40.61 \%$, QAR/KRW produced a staggering cumulative return of $332.52 \%$, increasing from $-26.84 \%$ under the carry trade. This great improvement in the QAR/KRW cumulative return indicates the forecasting model did its job by capturing large movements in exchange rate.

Table 2. Cumulative results

\begin{tabular}{|c|c|c|}
\hline & $\mathrm{CT}$ & FC \\
\hline MAE & 1.83 & 7.25 \\
\hline MSE & 7.17 & 91.22 \\
\hline RMSE & 2.57 & 9.33 \\
\hline $\mathrm{U}$ & & 3.79 \\
\hline Average Interest Differential & & 2.35 \\
\hline Direction Accuracy & - & $53.45 \%$ \\
\hline Confusion Rate & - & $46.56 \%$ \\
\hline Mean Return & 0.51 & 3.60 \\
\hline Cumulative Return & 5.04 & 83.51 \\
\hline Standard Deviation & 2.60 & 2.56 \\
\hline Sharpe Ratio & 0.35 & 1.32 \\
\hline VaR 99\% & 6.82 & 5.29 \\
\hline VaR 95\% & 3.75 & 3.22 \\
\hline
\end{tabular}


When comparing volatility, the carry trade showed, on average, a higher standard deviation of 2.60 compared to 2.56 for the forecasting-based strategy. QAR/KRW showed the highest standard deviation in both the carry trade and the forecasting-based strategy, with 3.85 and 3.66, respectively. With the Sharpe ratio being the most common risk-adjusted ratio investors consider, the forecasting-based strategy improved that ratio in five of six pairs, with QAR/KRW as the most improved among the pairs. The average Sharpe ratio for the six pairs under the carry trade was 0.35 while that average improved to 1.32 under the forecasting-based strategy. As concluded by Moosa (2008) and Moosa and Halteh (2012), a higher interest rate differential does not necessarily mean a higher return. It can be seen that, despite JPY/QAR having the largest interest rate differential of 3.68\%, it did not produce the highest mean annual return. Moreover, the QAR/KRW interest rate differential of $1.98 \%$ produced a negative mean annual return of $-1.92 \%$.

Concerning direction accuracy, the forecasting-based model provided five pairs with an accuracy level of more than $50 \%$ and only one pair with an accuracy level of less than 50\%. Comparing these results to the mean returns, four of the five pairs with accuracy rates above 50\% improved their mean returns; the only one that did not was SGD/QAR. Although CAD/QAR had direction accuracy less than 50\%, its mean return improved. A correlation test between accuracy rate and mean return showed a statistically significant positive relation at the $95 \%$ confidence level with an $R^{2}$ of 0.82 and a P-value of 0.046 .

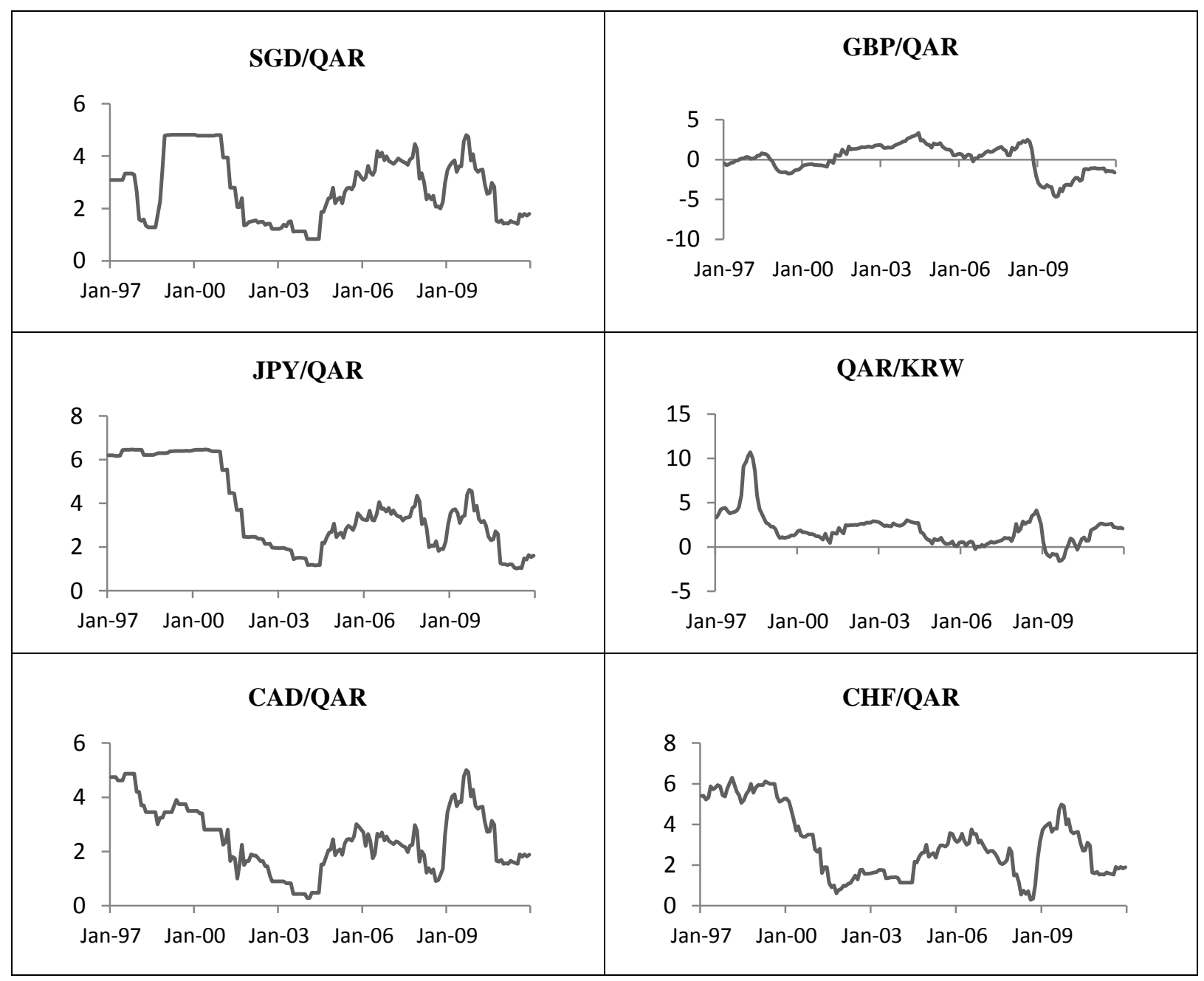

Figure 1. Interest rate differential 


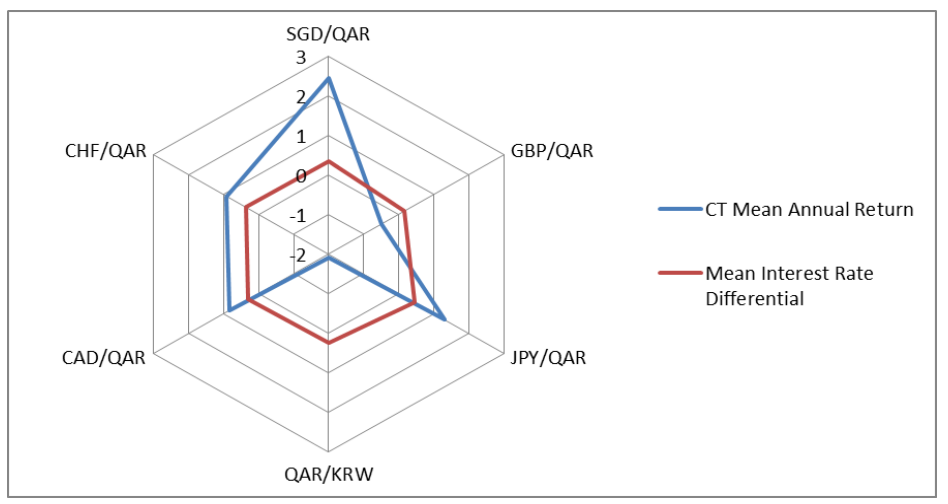

Figure 2. Interest rate differential vs. mean return

Concerning value-at-risk $(\mathrm{VaR})$ at the $99 \%$ confidence level, the forecasting-based strategy improved it in four pairs of the six pairs under consideration. QAR/KRW showed the most improvement, from $11.61 \%$ to $5.29 \%$. At the 95\% confidence level, VaR improved in five of the six pairs while SGD/QAR was the only pair with a higher expected loss in the forecasting-based model than in the carry trade model. In all, the forecasting-based strategy improved the average VaR at both the $99 \%$ confidence level, for which the average for the six pairs declined from $6.82 \%$ to $5.29 \%$, and at the $95 \%$ confidence level, for which the average declined from $3.75 \%$ to $3.22 \%$.

\section{Conclusion}

The results presented in this paper show that using Qatari riyal in a carry trade in its simplest form produced positive returns. In addition, using forecasting techniques improved both profitability and the risk-adjusted return. By using six currency combinations, with the Qatari riyal in each one of the pairs, profit was made in four of the six pairs when the interest rate differential alone was the selection criterion, and the number of profitable pairs increased to six of six when a forecasting technique was introduced. We also conclude that the interest rate differential is not associated with profit, confirming Moosa (2008) and Moosa and Halteh (2012) findings.

The findings of this paper also support Meese-Rogoff (1983) in that no macroeconomic forecasting model can outperform the naïve random walk in terms of the magnitude of error measures such as root mean square error. On the other hand, in terms of profitability, the monetary model showed it can perform well in generating better returns than random walk. This result answers the question of Chow et al. (2007) concerning why profit-maximizing firms pay huge amounts of money to purchase forecasting models. However, despite the success and popularity of carry trade among traders and investors, "the reasons for the success of the carry trade remain a bit of a mystery" ("Economics Focus," 2007).

\section{References}

Baillie, R., \& Chang, S. (2011). Carry Trades, Momentum Trading and the Forward Premium Anomaly. Journal of Financial Markets, 14(3), 441-464. http://dx.doi.org/10.1016/j.finmar.2011.01.001

Barroso, P., \& Santa-Clara, P. (2013). Beyond the Carry Trade: Optimal Currency Portfolios. http://dx.doi.org/10.2139/ssrn.2041460

Bhatti, R. (2012). On Return and Risk in Carry Trades: A Case of the Pak Rupee. International Journal of Economic and Finance Studies, 4(2), 201-214.

Brunnermeier, M., \& Pedersen, L. (2009). Market Liquidity and Funding Liquidity. Review of Financial Studies, 22(6), 2201-2238. http://dx.doi.org/10.1093/rfs/hhn098

Burnside, C., Eichenbaum, M., Kleshchelski, I., \& Rebelo, S. (2011). Do Peso Problems Explain the Returns to the Carry Trade? Review of Financial Studies, 24, 853-891. http://dx.doi.org/10.1093/rfs/hhq138

Burnside, C., Eichenbaum, M., Kleshchelski, I., \& Rebelo, S. (2006). The Returns to Currency Speculation. NBER Working Paper, No. 12489.

Burnside, C., Eichenbaum, M., Kleshchelski, I., \& Rebelo, S. (2007). The Returns to Currency Speculation in Emerging Markets. American Economic Review, 97(2), 333-338. http://dx.doi.org/10.1257/aer.97.2.333

Cheung, Y., Chinn, M., \& Garcia, A. (2005). Empirical Exchange Rate Models of the Nineties: Are Any Fit to Survive? Journal of International Money and Finance, 24, 1150-1175. http://dx.doi.org/10.1016/j.jimonfin.2005.08.002 
Chow, K., \& Tan, K. L. Y. (2007). The Use of Profits as Opposed to Conventional Forecast Evaluation Criteria to Determine the Quality of Economic Forecasts. Singapore: Nanyang Business School, Nanyang Technological University.

Darvas, Z. (2009). Leveraged Carry Trade Portfolios. Journal of Banking and Finance, 33(5), 944-957. http://dx.doi.org/10.1016/j.jbankfin.2008.10.007

Della Corte, P., Sarno, L., \& Tsiakas, I. (2009). An Economic Evaluation of Empirical Exchange Rate Models. Review of Financial Studies, 22, 3491-3530. http://dx.doi.org/10.1093/rfs/hhn058

Duni, C., \& Miao, J. (2007). Trading Foreign Exchange Portfolios with Volatility Filters: The Carry Trade Model Revisited. Applied Financial Economics, 17(3), 249-255. http://dx.doi.org/10.1080/09603100500447578

Economics Focus: Carry on Speculating. (2007, February 22). The Economist.

Engel, C., \& Hamilton, J. (1990). Long Swings in the Dollar: Are They in the Data and Do Markets Know It?. American Economic Review, 80, 689-713.

Gyntelberg, J., \& Remolona, E. (2007). Risk in Carry Trade: A Look at Target Currencies in Asia and the Pacific. BIS Quarterly Review, 4, 73-82.

Jorda, O., \& Taylor, A. (2012). The Carry Trade and Fundamentals: Nothing to Fear but FEER Itself. Journal of International Economics, 88(1), 74-90. http://dx.doi.org/10.1016/j.jinteco.2012.03.001

Jurek, J. (2014). Crash-neutral Currency Carry Trades. Journal of Financial Economics, 113(3), 325-347. http://dx.doi.org/10.1016/j.jfineco.2014.05.004

Jylhä, P., \& Suominen, M. (2011). Speculative Capital and Currency Carry Trades. Journal of Financial Economics, 99(1), 60-75. http://dx.doi.org/10.1016/j.jfineco.2010.07.006

Leitch, G., \& Tanner, J. (1991). Economic Forecast Evaluation: Profit Versus the Conventional Error Measures. American Economic Review, 81, 580-590.

Li, M. (2011). An Evaluation of Exchange Rate Models by Carry Trade. Journal of Economics and International Finance, 3, 72-87.

Meese, R., \& Rogoff, K. (1983). Empirical Exchange Rates Models of the Seventies: Do They Fit Out of Sample? Journal of International Economics, 14, 3-24. http://dx.doi.org/10.1016/0022-1996(83)90017-X

Menkhoff, L., Sarno, L., Schmeling, M., \& Schrimpf, A. (2012). Carry Trades and Global Foreign Exchange Volatility. Journal of Finance, 67(2), 681-718. http://dx.doi.org/10.1111/j.1540-6261.2012.01728.x

Moosa, I. (2004). What Is Wrong with Market-Based Forecasting of Exchange Rates? International Journal of Business and Economics, 3(2), 107-121.

Moosa, I. (2008). Risk and Return in Carry Trade. Journal of Financial Transformation, 22(3), 8-13.

Moosa, I. (2010). The Profitability of Carry Trade. Economia Internazionale, 63, 261-380.

Moosa, I. (2013). Why Is It so Difficult to Outperform the Random Walk in Exchange Rate Forecasting? Journal of Applied Economics, 45, 3340-3346. http://dx.doi.org/10.1080/00036846.2012.709605

Moosa, I., \& K. Burns. (2012). Can Exchange Rate Models Outperform the Random Walk? Magnitude, Direction and Profitability as Criteria. Economia Internazionale, 65(3), 473-490.

Moosa, I., \& Halteh, P. (2012). The Profitability of Carry Trade Relative to a Forecasting-Based Strategy. Journal of International Economics, 65(4), 605-621.

Schmidbauer, H., Rösch, A., Sezer, T., \& Tunalıglu, V. (2010). Currency Carry Trading with MGARCH Based Carry-to-Risk Portfolio Optimization. Proceedings of the 30th International Symposium on Forecasting ISF2010, San Diego, June 20-23.

West, D., Edison, H., \& Cho, D. (1993). A Utility-Based Comparison of Some Models of Exchange Rate Volatility. Journal of International Economics, 35, 23-45. http://dx.doi.org/10.1016/0022-1996(93)90003-G

\section{Copyrights}

Copyright for this article is retained by the author(s), with first publication rights granted to the journal.

This is an open-access article distributed under the terms and conditions of the Creative Commons Attribution license (http://creativecommons.org/licenses/by/3.0/). 